University of Wollongong

Research Online

Faculty of Social Sciences - Papers (Archive) Faculty of Arts, Social Sciences \& Humanities

2014

The impact of neighbourhood crime on physical activity: Evidence from

203,883 Australians

Gregory Kolt

Western Sydney University

Thomas E. Astell-Burt

University of Wollongong, thomasab@uow.edu.au

Xiaoqi Feng

University of Wollongong, xfeng@uow.edu.au

Follow this and additional works at: https://ro.uow.edu.au/sspapers

Part of the Education Commons, and the Social and Behavioral Sciences Commons

Research Online is the open access institutional repository for the University of Wollongong. For further information contact the UOW Library: research-pubs@uow.edu.au 


\title{
The impact of neighbourhood crime on physical activity: Evidence from 203,883
} Australians

\author{
Abstract \\ Abstract presented at Be Active 2014, 15-18 October 2014, Canberra, Australia \\ Keywords \\ 203, impact, australians, neighbourhood, evidence, activity, crime, physical, 883 \\ Disciplines \\ Education | Social and Behavioral Sciences

\section{Publication Details} \\ Kolt, G. S., Astell-Burt, T. \& Feng, X. (2014). The impact of neighbourhood crime on physical activity: \\ Evidence from 203,883 Australians. Journal of Science and Medicine in Sport, 18 (Supplement 1), \\ e147-e148.
}




\title{
The impact of neighbourhood crime on physical activity: Evidence from 203,883 Australians
}

\author{
G.S. Kolt ${ }^{1}$, T. Astell-Burt ${ }^{1}$, X. Feng ${ }^{2}$ \\ ${ }^{1}$ School of Science and Health, University of Western Sydney, Australia \\ ${ }^{2}$ School of Medicine, University of Western Sydney, Australia
}

Background: Interest in crime as a determinant of health has increased, yet with equivocal findings. Higher crime rates have been associated with lower levels of moderate-to-vigorous physical activity (MVPA) in some studies but not all. These inconsistent findings might relate to geographic scale, where larger aggregations of ecological data may hide smaller pockets of proximal crime that could have more powerful impacts on behaviour. This study examined the extent to which neighbourhood crime is associated with MVPA, and to determine whether crime measured locally has a stronger impact on MVPA than a measure that takes into account a wider context.

Methods: Data $(N=203,883)$ were drawn from the baseline survey of The 45 and Up Study, a large-scale cohort study of health and social phenomena across New South Wales, Australia. MVPA was assessed with the Active Australia Survey. The NSW Bureau of Crime Statistics and Research supplied crime counts for the same period in which The 45 and Up Study data were collected (2006-2009 inclusive), aggregated to the level of Census Collection District (CCD, comprising 300 residents on average) and Statistical Local Area (SLA, 36,000 residents on average). Five types of crime count were considered: total crime; non-domestic violent assaults; break and enter; malicious damage to property; and stealing, theft and robbery. Association between MVPA and crime was assessed using multilevel models, adjusting for individual-level sociodemographic variables and area-level confounders.

Results: Lower mean MVPA session counts were observed in areas with more crime at the CCD scale, with the exception of non-domestic violence. By contrast, little difference in MVPA was evident when crime was measured at the SLA scale. After adjusting for confounders, people living in CCDs with more crime participated less in weekly MVPA, and crime measured at the SLA were, by contrast, substantively weaker. Compared to those living in CCDs with zero crime, for example, those in CCDs with high overall crime had an Incidence Rate Ratio (IRR) of 0.90 ( $95 \% \mathrm{Cl} 0.85,0.97)$. At the SLA scale, those in high crime areas had an IRR of 0.97 ( $95 \% \mathrm{Cl} 0.95,0.99)$.

Discussion: These findings support the hypothesis that inconclusive results obtained in previous research on crime and health may be due, at least in part, to issues related to geographic scale. Thus, while crime in the wider environs should not be ignored, our results suggest that it is crime in the more local area that discourages physical activity. 